\title{
BLENDED LEARNING STUDENT PERCEPTION OF FACE-TO-FACE AND ONLINE EFL LESSONS
}

\author{
Brenda M.Wright \\ University Malaysia Sabah \\ bmwrightjapan@yahoo.co.nz
}

First received: 3 June 2016

Final proof received: 30 May 2017

\begin{abstract}
With the ever-increasing development of technology, online teaching is more readily accepted as a viable component in teaching and learning, and blended learning, the combining of online and faceto-face learning, is becoming commonplace in many higher education institutions. Blended learning is, particularly in developing countries, in its early stages and not without its challenges. Asynchronous online lessons are currently still more prevalent in many areas of South-East Asia, perhaps due to potential difficulty in obtaining strong Internet connections, which may deter educators from synchronous options. Technological media have the potential to broaden the scope of resources available in teaching and to enhance the language learning experience. Although research to date shows some focus on blended learning, literature on distance online teaching seems more prevalent. This study exposed 112 Malaysian undergraduate EFL students' responses to an online lesson as part of an English grammar course, and investigates common student perceptions of the online lesson as compared with face-to-face lessons. Questionnaires using qualitative (Likert scale questions) and quantitative (open-ended questions) approaches provided data for content analysis to determine common student perceptions, with particular reference to motivation and interest. In general, more students associated in-class lessons with higher motivation and more interest, due to better understanding, valued classroom interaction with the lecturer and peers, and input from the lecturer. Students preferring the online lesson cited speed and convenience of study and flexibility of time and place of study as reasons for their choice. Skilful implementation of online lessons can enhance a language course but should not undermine the value of face-to-face instruction with EFL teachers.
\end{abstract}

Keywords: blended learning; student perceptions; face-to-face; online; EFL lessons

The term 'blended learning' is a relatively new term, emerging in parallel with the development of the $21^{\text {st }}$ century technology. Various definitions of blended learning exist, and commonly in higher education, it is known as a combination of traditional face-to-face teaching and on-line teaching. Researchers however, have pointed to the complexities involved in accurately defining blended learning. Oliver and Trigwell (2005) argued that the focus should be on teaching rather than learning, offering a definition related to learning with blended pedagogies or media. Garrison and Kanuka note "virtually limitless design possibilities and applicability to so many contexts" (2004, p. 96) as confounding a definition, and settle on an experiential focus, citing "integration of classroom face-to-face learning experiences with on-line learning experiences" as their definition, while Bliuc, Goodyear, and Ellis, linking methodology and blended learning studies in a review of literature, saw blended learning as "a combination of co-present (face-to-face) interactions and technologically-mediated interactions between students, teachers and learning resources" (2007, p. 234). For the purpose of this study, which uses an asynchronous online medium, blended learning takes the simpler definition of online teaching integrated with face-to face learning. While research to date on distance learning and student perceptions of online learning is considerable, studies of online EFL classes that are supplementary to regular residential classes are less prolific. This study addresses this paucity and explores a comparison of student preferences and attitudes concerning the two lesson types, and with the objective of selecting a holistic method of study without undue complexity, a multi-task approach was employed in an online lesson focusing on modality.

\section{Blended learning: Friend or foe?}

Computer Assisted Language Learning (CALL) technologies and Learning Management Systems (LMS) continue to advance in sophistication. However, some researchers question aspects of their suitability for higher education and language teaching. Naidu pointed out that LMS lack "the tools and capability [for] the development of complex cognitive and social skills" (2006, p. 45), and Levy also cautioned against institution-wide adoption of LMS which satisfies technology integration requirements but may not "meet the pedagogical aspirations of faculty and local needs, such as those required in L2 teaching and learning" (2009, p. 779). Similarly, task or activity selection, 
whether online or in-class, may or may not be conducive to learning, as remarked by Garrett: "providing students with web links to authentic materials does not of itself constitute CALL. The real challenge is ... developing the activities that will integrate the content of authentic materials into the language learning process and engage students" (2009, p. 723). In other words, how to teach may be equally as important as what to teach for online language lessons and an apropriate balance of media input is paramount. As noted by Clark and Mayer, an overload of text, audio, and visual input can be detrimental to learning, as can a lack of input, for instance with a "wall-of-words approach" (2011, p. 19).

Another obvious disadvantage of online asynchronous lessons is the lack of verbal and nonverbal cues that may enrich teacher-student communication, particularly in language learning. Gestures, body language, and other audible cues enhance classroom communication and point to understanding or the lack thereof and are thus a contributing factor in determining class pace. Vrasidas and McIsaac (2000) pointed to the absence of rich communication cues as being one of the major disadvantages of computer-mediated communication.

In countries such as Malaysia, where consistently reliable internet connections are not a given, technical challenges can also be an issue for students and may prove disruptive to timely online study. Ginosyan and Tuzlukova (2014), for instance, using an asynchronous online study as a research focus, cited computer availability and reliable Internet connection as factors influencing effective participation for students in online discussion forums in Oman.

While some researchers debate over skills development and online study, efficacy of language learning online, and suitability of online materials to achieve pedagogical goals, others point to the benefits of CALL and blended learning in general, while still other researchers find little or no effect on learning outcomes for the different learning mediums.

In a face-to-face environment, students lose opportunities to communicate, unless they are selfassured and can respond quickly, whereas asynchronous online learning provides the learner with time to reflect and compose answers. As suggested by Garison and Kanuka (2004), who considered the transformative potential of blended learning in higher education, a combination of inclass and online learning can be complimentary and motivating for students, given that lesson design is effective and creative. Lim, Morris, and Kupritz (2007), in a study of undergraduates and online vs. blended learning satisfaction, concluded that the format of instructional delivery (either online or blended) may not necessarily affect learning to any significant degree. Similarly, Golonka, Bowles, Frank, Richardson, and Freynik (2012), in a review of 350 studies on technology and foreign language teaching, found only "moderate support for claims that technology enhanced learners' output and interaction, affect and motivation, feedback, and metalinguistic knowledge" (2012, p. 70). Bernard, Borokhovski, Schmid, Tamim, and Abrami (2014) contested that for achievement outcomes, blended learning surpasses classroom instruction. In their thorough meta-analysis study of 96 pieces of research on over 10,000 higher education students, they highlighted dependency on the type of computer support used along with 'interaction treatments' (student-student/-teacher/-content interaction) as being factors of importance in enhanced achievement. As seen above, research on blended learning and its success is much and varied. Although there appears to be no definitive consensus in literature as to the value of blended learning, it is undeniably a pervasive force in modern teaching, and one that deserves further study.

\section{Student perception and satisfaction with online lessons}

The importance of student perception has been stressed in research investigating the quality of blended learning. Ginns and Ellis (2007), for instance, in an extensive meta-analysis study, linked positive student perceptions of blended learning with comparatively higher grades, and concluded that teachers using blended learning must understand student perceptions of online learning and how it supports learning across a whole course.

Analysis of student satisfaction with online lessons has covered a wide ground and can be seen by some researchers as playing a vital role in determining the success of CALL. Links of student motivation and online lessons, for instance, are cited by Van der Merwe (2007). Similarly, Pollard (2015) found online study using a web 2 portal had positive effects on Korean EFL learners in terms of motivation and provided beneficial opportunities for autonomous learning.

However, in research analysing more than 20 articles on distance learning, Allen, Bourhis, Burrell, and Mabry (2002) found no significant difference in student satisfaction for online or traditional in-class learning. Other research findings similarly show equal satisfaction with online and face-to-face courses (Driscoll, Jicha, Hunt, Tichavsky \& Thompson, 2012). The implication here may be that in recent times, technophilic students are familiar with blended learning, and in general are equally satisfied with both online and face-to-face lessons.

Self-pacing/flexibility in timing and study
location
Self-pacing has been found to be an important


element of online learning, with students valuing the freedom to study at their own pace (Schrum, 1995). In a classroom situation, variance of aptitude levels is a factor influencing students' study pace. Having more time to respond online than in a traditional classroom context may increase student motivation and participation, especially in shy students (Spodark, 2001). In a review of 76 articles concerning online study, one group of researchers concluded that, despite self-management challenges, students prefer to study at their own paces, and that convenience and student autonomy were two benefits of online study (Tallent-Runnels, Thomas, Lan, Cooper, Ahern, Shaw, \& Liu, 2006). Time to reflect on materials before responding was also a benefit cited by researchers in distance learning (Matthews, 1999; Simonson, Smaldino \& Zvacek, 2000; Aharony, 2011). The same benefit may also be applicable to online lessons, where students are less pressured to respond speedily to questions, for instance. In this way, the fundamental element of flexibility of timing of asynchronous CALL holds appeal for both students and teachers. Similarly, a gain in flexibility of study place is practical and desirable for students with transport challenges or schedule pressures.

As blended learning is still relatively new in general teaching practice, especially in developing countries, there is a need for more research in this field, in both theory and practice, especially for campus-based students. In a review of online and blended course research to date, Tallent-Runnels et al. (2006) pointed to the need for researchers to strengthen theories; for instance, theories of student motivation, as well a need for more experimental research as opposed to descriptive research, in order to improve research quality. Similarly, Bliuc et al. (2007) argued that blended learning research needs to focus on the nature of how to integrate modes of learning such as face-to-face and on-line and consider the quality of students' learning experiences. With these points in mind, the current study aims to provide some insight into student perception of how an online grammar lesson compares with a face-to-face lesson, to discern what common themes appear in student evaluations of the lessons with reference to interest and motivation, and to look at how the blended learning experience can contribute to EFL learning.

\section{METHOD}

\section{Context and research procedure}

The current study uses a student-centred approach and was conducted to ascertain student attitude and perceptions regarding online lessons in comparison with face-to face lessons. The online lesson was delivered to 112 undergraduate students (4 classes) at a Malaysian public university. The students were attending a 'Communicative English Grammar' course. The students were of band 1, 2 and 3 of the MUET, university entrance examination level, or elementary to pre-intermediate level of proficiency. The course, primarily designed to be conducted in face-to-face classes, also accommodated the inclusion of online lessons; the platform for which was a university learning management system (SMART 2).

Meeting the challenge of matching the delivery medium with performance objectives, as well as ensuring participant commitment and follow up, the online lesson included a range of materials and activities. Included in the online lesson were: guidelines for how to complete the online lesson; an introductory video by the lecturer explaining modals for ability, permission and requests; a video link to a YouTube video "No Arms No Legs No Worries Nick Vujicic"; a comprehension quiz related to the video; and assessment exercises from text book Focus on Grammar 3 (Fuchs, Bonner \& Westheimer, 2006). Answers to the quiz and exercises were discussed in the following lesson, when students were asked to fill in a feedback questionnaire detailing their perceptions of the online lesson.

\section{Research design, analysis and instrument}

The study employed quantitative and qualitative design approaches for triangulation, the analysis instrument being a questionnaire consisting of Likert scale questions, dichotomous questions, and open-ended questions. Quantitative data generated by the dichotomous and Likert scale questions were analysed using descriptive statistics and frequency analysis. Qualitative data content, i.e. responses to open-ended questions, were analysed and coded into emergent categories and sub-categories. Content analysis (Neuendorf, 2002) was used because it was not obtrusive, fitted the specific context of the study, and was suitable for a large quantity of data. Units of meaning for the qualitative analysis were phrases, sentences or more than one sentence indicating one category or sub-category item.

Aspects of the student feedback investigated included: the general preferences of students for online or face-to-face lessons, common student perceptions of the online lesson in terms of motivation, and common student perceptions of the online lesson in terms of interest.

\section{FINDINGS}

\section{General preferences and lesson types}

More students indicated a general preference for face-to-face lessons. Of the 112 respondents, 42 students, or $37.5 \%$, showed preference for the online lesson as compared with a total of $58 \%$ of students who preferred face-to-face lessons. In addition, 5 students, or $4.5 \%$ of the total sample, indicated preferences for both types of lessons. 
Table 1. General preference for online lesson or face-to-face lesson $(\mathrm{n}=112)$

\begin{tabular}{lcc}
\hline Preference for Lesson & Number of Students & Percentage \\
\hline Face-to-Face & 65 & $58.0 \%$ \\
\hline Online & 42 & $37.5 \%$ \\
\hline Both Online and Face-to-Face & $\mathbf{5}$ & $\mathbf{4 . 5 \%}$ \\
\hline
\end{tabular}

Reasons given by students for their preferences as a response to an open-ended question revealed several common themes. Students indicating a preference for regularly scheduled, in- class lessons, or $58 \%$ of the respondents, cited the following themes (categorised and ordered for prevalence) in their reasoning:

- enhanced understanding

- more or easier understanding

- interaction with lecturer or students

- more details, more input or explanation by lecturer

- lecturer helps, guides

- can ask lecturer or other students directly if confused

- can interact with lecturer or other students

- enjoyment

- interesting, happening, alive

- teaching style

- focus

- no need for internet connection

- longer time

Preferences for the online lesson, which accounted for $42 \%$ of the students, fell into categories (ordered for prevalence) related to convenience, comfort or enjoyment, and skills improvement:

- comfort, convenience of time and location

- shorter time

- more flexible timing

- don't have to hurry to class

- flexible location

- relaxed (in own room, in library with good air-con)

- ability to repeat video

- enjoyment

- interesting

- fun, exciting

- different

- ease to focus

- skills enhancement
- can easily get information about the subject

- independent study opportunity

- English skill improvement

In sum, students preferring the face-to-face lessons indicated the main reasons for their choice were that they gain better understanding in a classroom context, due to opportunities for interaction to clarify grammar explanations with the lecturer or other students; and that the lessons were more enjoyable. The main reasons given by students preferring the online lesson were connected with comfort and convenience (of time and location) and enjoyment.

\section{Lesson types and motivation}

Findings for the Likert scale questions concerning students' motivation and the differing lessons revealed in general that students perceived that they were somewhat more highly motivated during the face-to-face lessons. Totalled data for 'strongly agree' and 'agree' categories show that $64.3 \%$ felt more motivated during the face-to-face lesson, while $57.1 \%$ of students were more motivated during the online lesson. A higher percentage of students strongly agreed that they were more motivated during in-class lessons $(23.2 \%)$, as compared with those who found the online lesson more motivating (12.5\%). The 'agree', category, although inconsistent with the general trend, provided similar percentages for the 2 lesson types ( $41.1 \%$ and $44.6 \%$ respectively).

It may be pertinent to take into account that students' motivation could have been influenced by the novelty of the online lesson. Similarly, although not a major focus in the questionnaire, poor internet connection could have been a factor negatively influencing motivation--indeed some students reported internet connection problems as troublesome.

Table 2. Motivation and lesson type $(n=112)$

\begin{tabular}{lcccccc}
\hline \multicolumn{1}{c}{ Item } & $\begin{array}{c}\text { Strongly } \\
\text { agree }\end{array}$ & Agree & Neutral & Disagree & $\begin{array}{c}\text { Strongly } \\
\text { agree }\end{array}$ & No response \\
\hline $\begin{array}{l}\text { Motivation higher for in- } \\
\text { class lesson }\end{array}$ & 23.2 & 41.1 & 29.5 & 0.9 & 0 & 5.3 \\
\hline $\begin{array}{l}\text { Motivation higher for } \\
\text { online lesson }\end{array}$ & 12.5 & 44.6 & 34.8 & 3.6 & 0 & 4.5 \\
\hline
\end{tabular}

The students were asked to detail reasons for their choices concerning motivation, interest, and lesson type using an open-ended question. Firstly, a notable result was from those students whose reasons indicated that both types of lesson were motivating ( $16 \%$ of responses), given that the 
questionnaire had requested an either response. Open-ended question responses giving reasons for face-to-face lesson motivation stood at $51 \%$ and online $33.3 \%$, reflecting the previously mentioned trend for face-to-face learning preferences.

Reasons for in-class motivation, when categorised and sorted for commonality, fitted 3 main themes of general motivation, enhanced understanding. and the benefits of classroom interaction, along with less frequently cited themes of skills enhancement, discipline, and classroom environment. The categories, detailed below are ordered in decreasing prevalence:

- general motivation

- improved understanding

- more/easier understanding

- online lesson hard to understand

- lecturer gives more example/details

- classroom interaction

- can study face-to-face with lecturer

- can ask or discuss with lecturer or classmates if don't understand

- lecturer or friends make(s) me motivated

- skills enhancement

- learn new language skills, new experiences

- can improve speaking

- can be brave and speak English

- discipline

- can manage my time properly

- students more disciplined in front of teacher

- higher self-motivation

- classroom environment

- interesting

- happy and relaxed

- can focus on subject

Motivation connected with online lesson preferences was attributable mainly to themes of general motivation, speed of completion, motivational video content, time management, studying alone, interest, and learning about English and technology at the same time. This feedback, gained from open-ended question data, is outlined below in categories and sub-categories for motivation and online lesson choices, in descending frequency.

- general motivation

- speed of completion

- motivational video content

- time or location management

- flexible time or easy to study

- free WiFi at hostel

- no need to carry books around

- studying alone

- interest, enjoyment, fun

- learning about English and technology at the same time

- can search other information online

- mood on the day

- focus enhanced

Worthy of note is one anomaly in results. Several respondents cited the video content (a documentary clip on motivational speaker Nick Vujicic) as being motivational rather than addressing the question of how the online lesson as a whole was motivational. It should also be noted that comments such as "easy to do" were somewhat ambiguous, relating either to convenience i.e. that lessons could be done with time and location flexibility using $\mathrm{WiFi}$, or conversely that the lesson was easy.

\section{Lesson types and interest}

Data compiled concerning students' interest levels showed similar trends as those of motivation, with perception of interest being higher for in-class lessons (25\% reported 'strongly agree' and 45\% 'agree'), whereas for the online lesson less interest was shown (19.6\% agreed strongly and $43.8 \%$ reported agreement).

Table 3. Interest and lesson type $(\mathrm{n}=112)$

\begin{tabular}{lcccccc}
\hline Item & \multicolumn{5}{c}{ Likert scale response (\%) } \\
\hline $\begin{array}{l}\text { Strongly } \\
\text { agree }\end{array}$ & Agree & Neutral & Disagree & $\begin{array}{c}\text { Strongly } \\
\text { agree }\end{array}$ & No response \\
\hline $\begin{array}{l}\text { Interst higher for in- } \\
\text { lesson higher for online }\end{array}$ & 25.0 & 45.5 & 21.4 & 0 & 0 & 8.1 \\
\hline
\end{tabular}

Open-ended question data on interest fell into three areas: interest in online lesson, interest in the regular in-class lessons, and interest in both kinds of lessons. Some students, indeed $16.8 \%$ of all respondents, provided information as to why they were interested in both lesson types. Students who felt the face-to-face lessons were more interesting, numbering $50.4 \%$ and $32.8 \%$ of respondents, thought the online lesson more interesting.

Students selecting in-class lessons as being of more interest cited general interest, enhanced understanding, and lecture activities as main reasons for their choice. Themes for more interest in face-to face lessons, listed according to prevalence, are presented below.

- general interest

- better understanding

- lecturer helps/explains

- can ask when don't understand

- more notes/information 
- easier to understand

- lecturer does activities

- can study/communicate with lecturer/other students

- learn new things

- online boring/WiFi always down

Students who were more interested in the online lesson gave flexibility (of time and place), general interest, novelty, and using the internet as the main reasons for their selection. Below are listed these students' reasons, grouped according to commonality.

- flexible time and place to study

- general interest

- something new

- internet use

- videos and pictures

- free WiFi at hostel

- can use Google translate

- can check online for more information

- exciting/fun/creative

- challenging

- can study alone

Although students pointed to the novelty of using the internet as a bonus in this study, it is worth keeping in mind that the online lesson was a one-off lesson, and if repeated regularly, may lose this novelty effect.

\section{DISCUSSION}

Despite revealing findings useful in contributing to the current body of research on blended learning, this study was limited to a relatively small population of EFL students and a single online lesson. Future studies utilising a broader population and longer timeperiod, as well as a wider scope of instructional focus are needed to compliment these findings that covered a limited area of grammatical lessons in a blended learning context. The current study was potentially subject to a 'novelty factor' bias for the online lesson. Perhaps a factor that could enhance a course due to the variation in routine, the online lesson could appear less favourable to students if it were more frequent. To further expand the findings of this study, more empirical evidence such as pre and post-lesson testing could be of use in looking into possible correlation between blended lesson types, learning, and student perceptions.

Despite these limitations, the present study has some implications for language practitioners who are integrating online lessons into regular campus-based lessons. It indicates that a studentcentred investigative approach may reveal useful data on student preferences and behaviour, in the context of blended learning, including aspects of motivation and interest, and that studies on online technology and materials can be complimented by seeking to understand students' perceptions of their learning environments. In line with Ginns and Ellis (2007), this study highlights the importance of understanding student perceptions of the online lesson and how they support learning within the framework of the whole course.

\section{General preferences}

Students preferring the in-class lesson, who numbered slightly more than those preferring the online lesson, commonly cited better understanding as a reason for their choice. From a pedagogical standpoint, this finding may hold implications for consideration of task fit and media usage. The need to match the correct media tool to the given study focus is an area of interest for further in depth study as specialised technologies continue to develop. An important component in online lessons, instructional videos are required to be both simple and comprehensible-these factors may be enhanced, for instance, with the incorporation of subtitles and the inclusion of PowerPoint slides for enhanced explanation.

Findings of this study also hold implications for instructional elements and methods of delivery. It is suggested that explanatory videos, such as the grammar rule introduction in the current study, be used in tandem with adequate pre-online-lesson-inclass explanation, and post-online-lesson follow up, enabling teachers ample time for student questions and rule clarification. A synchronous learning environment, if practical, where more timely feedback is possible, would also provide opportunity to support student understanding. However, despite concerns linked to understanding raised by some students, it is worth bearing in mind that similar concerns may exist in face-to-face lessons, and shy students may not necessarily ask for elucidation when surrounded by peers. In addition, as remarked in student feedback, the online lesson provided the challenge for students to study more independently, arguably a boon for students in their second semester at university. Incorporation of online learning options such as 'Englishlive/Englishtown' which link students with teachers online for individual or group video lessons, or applications and learning systems such as 'Tell me More English' or 'Transparent Language' for supplementary or online grammar instruction could provide opportunities for enhancement of motivation and EFL learning.

The issue of support may also be considered from a psychological viewpoint. Students preferring in-class lessons in general reported interaction and enjoyment as factors influencing their choice. Arguably, this concern of lack of support could have been a natural reaction to the new study environment and one which may alter with time. 
However, a sense of belonging, or opportunities for collaboration could be promoted by incorporating, for instance, an online wall posting activity, viewable to all students. As mentioned above, the other side of the coin is that students do need independent study, and must not simply rely on friends with more aptitude to provide answers, as can occur in some in-class situations in a culture that values group connectivity more highly than individualism.

\section{Motivation and interest}

Contrary to findings of researchers such as Van der Merwe (2007) and Pollard (2015), motivation and interest data analysis in this study points to a larger number of students generally associating in-class lessons with higher motivation and more interest, primarily due to better understanding, valued classroom interaction with the lecturer and peers, and input from the lecturer. In line with Vrasidas and McIsaac (2000) students perceived communication cues as being of importance in a holistic learning environment. Other themes explaining in-class motivation and interest included perceived opportunity to improve speaking skills, positive classroom environment, enhanced discipline, and reported problems connecting to the internet for the online lesson.

A smaller number of students were more motivated by or interested in the online lesson. Their reasons for preferring the online lesson included speed and ease of completing the work, with flexibility of time and place also being a major factor. The factor of self-pacing value in online lessons echoes the findings of Schrum (1995), Spodark (2001), and Tallent-Runnels et al. (2004). Students also cited motivational content, novelty, and the fun of using the Internet as factors that motivated them in the online study. The concern here to educators would be whether the motivational element correlated to learning outcomes, an area worthy of further study.

\section{CONCLUSION}

Taking into account the number of students who also reported that they were equally motivated by $(16 \%)$ and interested in $(16.8 \%)$ both kinds of lessons; and factors such as study habits, personality, convenience of travelling to university, intermittent WiFi connection; as well as the fact that many EFL instructors are trained primarily in language teaching not as technology experts; it would be reckless to claim that one lesson type is generally of more benefit than the other. Rather, it is suggested that online lessons can be skilfully incorporated into existing in-class courses, if necessary attention is given to suitability of materials and technology, and, ideally, if necessary preparation and follow up is conducted in regular face-to-face classes. Instructors and students must take responsibility to engage fully in online teaching and learning opportunities. Rather than seeing online lessons as a way to avoid work or study, they should be implemented with the aim of delivering a motivating, interesting lesson that enables students' learning. In concurrence with Garrett (2009), it is suggested that to simply upload links as lesson components is not enough; well-rounded lessons with suitable activities and proof of participation should be devised. As remarked by Garison and Kanuka (2004), blended learning can have transformative power and spark motivation if used with the appropriate design compliment of online and in-class lessons. It follows that in countries whereby demands for online components in courses are new, adequate training in use of online platforms and how to integrate online tools and methodologies in learning must be made available to language professionals by their institutions, and adequate internet quality must also be provided. In conclusion, the use of online technology, materials and media in language learning must be skilfully implemented to enhance a course, but should not undermine the importance of face-to-face instruction with EFL teachers.

\section{REFERENCES}

Aharony, N. (2011). Library and information science students' feedback in an online course. Journal of Education for Library and Information Science, 52(4), 305-319.

Allen, M., Bourhis, J., Burrell, N., \& Mabry, E. (2002). Comparing student satisfaction with distance education to traditional classrooms in higher education: A meta-analysis. American Journal of Distance Education, 16(2), 83-97.

Bernard, R. M., Borokhovski, E., Schmid, R. F., Tamim R. M., Abrami, P. C. (2014). A metaanalysis of blended learning and technology use in higher education: fromFgeneral to the applied. Journal of Computing in Higher Education, 26, 87-122. DOI 10.1007/s12528013-9077-3.

Bliuc, A. M., Goodyear, P. \& Ellis, R. A. (2007). Research focus and methodological choices in studies into students' experiences of blended learning in higher education. Internet and Higher Education, 10(4), 231-244.

Clark, R. C., \& Mayer, R. E. (2011). E-learning and the science of instruction. Proven guidelines for consumers and designers of multimedia learning. Third edition. San Fransisco. Pfeiffer.

Driscoll A., Jicha, K., Hunt, A. N., Tichavsky, L. \& Thompson, G. (2012). Can online courses deliver in-class results? A comparison of student performance and satisfaction in an online versus a face-to-face introductory 
sociology course source. Teaching Sociology, 40(4), 312- 331.

Fuchs, M., Bonner, M., \& Westheimer, M. (2006). Focus on grammar 3: An integrated skills approach third edition. Pearson Education Longman: NY.

Garrett, N. (2009). Computer-assisted language learning trends and issues revisited: Integrating innovation. The Modern Language Journal, Focus Issue: Technology in the Service of Language Learning: Update on Garrett (1991) Trends and Issues, 93, pp. 719-740. Retrieved 18th November, 2015 from http://www.jstor.org/stable/25612270.

Garrison, D. R, \& Kanuka, H. (2004). Blended learning: Uncovering its transformative potential in higher education. Internet and Higher Education, 7, pp. 95- 105.

Ginns, P., \& Ellis, R. (2007). Quality in blended learning: Exploring the relationships between on-line and face-to-face teaching and learning. Internet and Higher Education, 10, 53- 64.

Ginosyan, H. \& Tuzlukova, V. (2014). Enhancing Omani university students' writing and study skills: Discussion forum module. Indonesian Journal of Applied Linguistics, 4(2), 56-67.

Golonka, E. M., Bowles, A. R., Frank, V. M., Richardson, D. L. \& Freynik, S. (2012). Technologies for foreign language learning: a review of technology types and their effectiveness. Computer Assisted Language Learning, 27(1), 70-105.

Levy, M. (2009). Technologies in use for second language learning. The Modern Language Journal, Focus Issue: Technology in the Service of Language Learning: Update on Garrett (1991) Trends and Issues, 93, pp. 769782. Retrieved 18th November, 2015 from http://www.jstor.org/stable/25612273.

Lim, D. H., Morris M, L., \& Kupritz V. W. (2007). Journal of Asynchronous Learning Networks, 11(2), 27- 42. Retrieved 5th April, 2016 from http://repositorio.ub.edu.ar:8080/xmlui/handle/
$123456789 / 2257$.

Matthews, D. (1999). The origins of distance education and its uses in the United States. $T$. H. E. Journal, 27(2), 54- 66.

Naidu, S. (2006). E-learning: A guidebook of principles, procedures and practices (2nd ed.). New Delhi: Commonwealth Educational Media Centre for Asia.

Neuendorf, K. A. (2002). The content analysis guidebook. Thousand Oaks: Sage.

Oliver, M., \& Trigwell, K. (2005). Can 'blended learning' be redeemed? E-learning, 2(1), 1726.

Pollard, A. (2015). Web-based journals in the classroom: Motivation and autonomous learning. Indonesian Journal of Applied Linguistics, 4(2), 20-31.

Schrum, L. (1995). Online courses: What have we learned? Paper presented at the World Conference on Computers in Education, Birmingham, UK.

Simonson, M., Smaldino, S., Albright, M. \& Zvacek, S. (2000). Teaching and learning at a distance: Foundations of distance education. Upper Saddle River, NJ: Merrill.

Spodark, E. (2001). Integrating online techniques into undergraduate french language instruction. The French Review, Special Issue on Pedagogy 74(6), 1206-1217.

Tallent-Runnels, M. K., Thomas, J. A., Lan, W. Y., Cooper, S., Ahern T. C, Shaw, S. M. \& X. Liu (2006). Teaching courses online: A Review of the research. Review of Educational Research, 76(1), 93-135.

Van der Merwe, A. (2007). Using blended learning to boost motivation and performance in introductory economics modules. South African Journal of Economics, 75, 125-135. DOI: 10.1111/j.1813-6982.2007.00109.x.

Vrasidas, C., \& McIsaac, M. (2000). Principles of pedagogy and evaluation of web-based learning. Educational Media International, 37(2), 105-111. 